\title{
EL APARTHEID GLOBAL, EL COYOTAJE Y EL DISCURSO DE LA MIGRACIÓN CLANDESTINA: DISTINCIONES ENTRE VIOLENCIA PERSONAL, ESTRUCTURAL Y CULTURAL
}

DAVID SPENER ${ }^{*}, 1$

RESUMEN: En este ensayo propongo una reorientación del discurso público y académico en torno a la migración internacional que se realiza de manera autónoma y fuera de la regulación del estado. Es típico de este discurso que presente una terminología y un marco temático que privilegien la perspectiva de las autoridades estatales respecto al fenómeno de los movimientos migratorios transfronterizos. En cambio, ofrezco un marco alternativo que considera a la migración autónoma como una forma de resistencia al apartheid global que se pone en práctica en las fronteras de los estados. Centro mi análisis en el coyotaje, el proceso social por el cual los migrantes contratan a proveedores profesionales de servicios para ayudarlos a cruzar las fronteras, dados los intentos de los estados por excluirlos. Dirijo mi atención específicamente a la manera en la cual deberíamos comprender la cuestión de la violencia que se inflige a los migrantes y en cómo evaluar quién o qué es responsable por esa violencia. En esa argumentación utilizo los conceptos de Galtung (1969 y 1990) de violencia personal, estructural y cultural para interpretar las tragedias, que con extremada frecuencia, acontecen a los migrantes en su utilización del coyotaje como estrategia de cruce de la frontera. La discusión de estos temas se basa principalmente en mi investigación de campo en torno a los cruces clandestinos de la frontera por parte de los mexicanos en el corredor migratorio del noreste de México y sur de Texas, a fines de los años noventa y principios de la presente década.

PALABRAS CLAVE: apartheid global; migración internacional; contrabando de personas; tráfico de personas; frontera México-Estados Unidos

\footnotetext{
* Trinity University.

${ }^{1}$ El autor agradece a la Trinity University y a la Fundación John D. y Catherine T. MacArthur por el generoso apoyo a la investigación y la reflexión que hicieron posible la publicación de este ensayo. Además, reconoce los valiosos comentarios a este texto realizados por los participantes en la reunión titulada "Migration and Human Rights in the North American Corridor» que se llevó a cabo en la Universidad de Chicago en octubre de 2007, así como los comentarios críticos de dos dictaminadores anónimos de Migración y Desarrollo.

NotA Del EDITOR: Traducción del inglés por Luis Rodolfo Morán Quiroz.
} 
ABSTRACT: In this essay I propose a re-orientation of the public and scholarly discourse about international migration that takes place autonomously, beyond the pale of state regulation. This discourse typically features a terminology and a framing of issues that privileges the perspective of state authorities regarding the phenomenon of cross-border migratory movements. In its stead, I offer an alternative framework that views autonomous migration as a form resistance to global apartheid enforced at nation-state borders. I focus my analysis on coyotaje, the social process by which migrants hire professional service providers to help them cross international boundaries in the face of states' attempts to exclude them. In particular, I direct my attention to how we should understand the question of violence inflicted upon migrants and how to assess who or what is responsible for that violence. In so doing, I make use of Galtung's (1969 and 1990) concepts of personal violence, structural violence, and cultural violence to interpreting the tragedies that too often befall migrants as they pursue coyotaje as a border-crossing strategy. Discussion of these issues is based primarily on my field research on the clandestine border-crossing experiences of Mexican nationals in the Northeast Mexico-South Texas migratory corridor in the late 1990s and early 2000s.

KEY WORDS: global apartheid; international migration; human smuggling; human trafficking; U.S.-Mexico border 
E

n este ensayo propongo una reorientación del discurso público y académico en torno a la migración internacional que se realiza de forma autónoma más allá del alcance de la regulación del estado. Este discurso, ya sea reproducido por los defensores de los inmigrantes o por los que pretenden restringir la inmigración, típicamente utiliza una terminología y un marco temático que privilegia la perspectiva de las autoridades estatales respecto al fenómeno de los movimientos migratorios transfronterizos. En cambio, me baso en varios conceptos en las principales literaturas sobre migración, desarrollo y derechos humanos para ofrecer un marco alternativo que concibe a la migración autónoma como una forma de resistencia al apartheid global, que se ejerce en las fronteras de los estados nación.

Más específicamente, centro mi análisis en el proceso social por el cual los migrantes contratan a proveedores de servicios profesionales o semi-profesionales para ayudarles a cruzar las fronteras, a pesar de los esfuerzos de los estados por excluirlos. En vez de los términos centrados en el estado de «contrabando» y «tráfico", me refiero a este proceso como coyotaje (proveniente de coyote, el término mexicano de mayor uso para estos proveedores de servicios) y enfatizo la manera en que éste constituye una estrategia de supervivencia buscada por los migrantes. Además, dirijo mi atención a las formas en que habríamos de entender la cuestión de la violencia inflingida a los migrantes, mientras atraviesan la frontera MéxicoEstados Unidos y cómo evaluar quién o qué es responsable de esa violencia. En esta argumentación utilizo los conceptos de Galtung (1969 y 1990) de violencia personal, violencia estructural y violencia cultural para interpretar las tragedias que acontecen con demasiada frecuencia a los migrantes mientras utilizan el coyotaje como estrategia de cruce de fronteras. La discusión de estos temas se basa principalmente en mi investigación de campo en torno a las experiencias clandestinas de cruce fronterizo por parte de los mexicanos en el corredor migratorio del noreste de México y del sur de Texas, a fines de los años noventa y principios del siglo XXI. ${ }^{2}$

\section{MARCO CONCEPTUAL}

Tanto en el discurso académico como en el discurso público más amplio es típico que los cruces clandestinos de la frontera por parte de los migrantes se discutan de formas que enfatizan cómo se viola la ley al expresar el derecho de los estadosnación soberanos a excluir a los no nacionales de sus territorios según consideren

\footnotetext{
2 Esta investigación cualitativa estuvo limitada a las experiencias de los migrantes mexicanos de regiones de origen en México con una larga tradición migratoria, en especial pequeños poblados y comunidades rurales en los estados de Guanajuato, Nuevo León y Jalisco. Se realizó entre 1998 y principios de 2006, en una parte de la región fronteriza de México-Estados Unidos cuyas características diferían de manera substancial respecto a aquellas que se dan en otras partes de la región
} 
conveniente. Esta forma de enmarcar los temas no reconoce de qué manera esas leyes expresan también las relaciones internacionales de poder de formas, que con frecuencia imponen un gran sufrimiento y privación para quienes son excluidos. Propongo aquí un marco alternativo que enfatiza cómo la exclusión forzada de los migrantes de ciertos territorios nacionales en el sistema mundial opera como instrumento de control y explotación de la mano de obra, mientras que las prácticas de los cruces clandestinos de las fronteras, por parte de los migrantes, representan una forma de resistencia a ese control y explotación.

La división del mundo en regiones con altos salarios, gran riqueza y gran bienestar frente a regiones de bajos salarios, escasa riqueza y escaso bienestar ha preocupado durante mucho tiempo a los científicos sociales. Uno de los conceptos más provocativos para interpretar esta división que ha surgido en décadas recientes es el de apartheid global (Alexander 1996; Booker y Minter 2001; Kohler 1978 y 1995; y Richmond 1994), el cual enfatiza de qué manera la mala distribución de los recursos y del bienestar en el mundo está fuertemente correlacionada con la raza y la nacionalidad. Desde esta perspectiva, el control sobre la movilidad y la fuerza de trabajo de las poblaciones no-blancas en el nivel internacional se trata como una analogía del tratamiento de los negros bajo el régimen de apartheid en Sudáfrica entre 1948 y 1994.

Como han hecho notar los autores que emplean el concepto de apartheid, la vigilancia en las fronteras, o lo que Heyman (1999) denota como interdicción, desempeña un papel crucial en el mantenimiento de las inequidades globales en la medida en que mantiene espacios sociales, políticos y económicos separados en el sistema mundial y restringe además la capacidad de los residentes empobrecidos, de trasladarse de una región a otra en busca de ingresos más altos y de mejores estándares de vida. Como he argumentado en otra parte (Spener 2006 y en prensa), la operación histórica y contemporánea de la frontera de México-Estados Unidos con respecto a la mano de obra mexicana puede tomarse como un ejemplo específico de la operación general del sistema global de apartheid. También es importante reconocer aquí que éste opera no sólo restringiendo el movimiento físico de los trabajadores mexicanos sino también negándoles derechos y haciéndoles vulnerables a la explotación cuando los designa como ilegales, si logran entrar al territorio de Estados Unidos a pesar de los esfuerzos del estado por detenerlos en la frontera (De Genova 2002:429). De tal forma, el apartheid global se expresa en América Latina como una segmentación militarizada del mercado de mano de obra dentro de una región transnacional, caracterizada por un mercado altamente integrado para otros bienes, servicios y capital.

como en los corredores de las dos Californias y de Arizona-Sonora. Entre mis informantes no estaban incluidos migrantes que trabajaran en la agricultura, en donde las relaciones entre los migrantes, los coyotes y los contratistas de mano de obra agrícola puede implicar niveles considerablemente mayores de abuso y explotación de los encontrados en mi trabajo de campo (véase Krissman 2000). Por esas razones, los hallazgos e interpretaciones reportadas en estas páginas no pueden ser directamente generalizadas a otras poblaciones en otras ubicaciones. 
Un segundo concepto que sirve de guía para mi investigación sobre el cruce clandestino de la frontera es el de migración internacional autónoma, propuesto por Néstor Rodríguez (1996: 22), para referirse al «movimiento de personas a través de las fronteras del estado nación fuera de las regulaciones del estado». Según Rodríguez, la autonomía migratoria significa que «las comunidades de clase trabajadora en los países periféricos han desarrollado sus propias políticas de empleo internacional independientes de la planeación interestatal». Los mexicanos procuran este tipo de migración como estrategia de supervivencia, por medio de la cual se resisten activamente al confinamiento territorial en una región de bajos salarios en la economía mundial, cruzando la frontera para trabajar en Estados Unidos, a pesar de los esfuerzos considerables que realizan las fuerzas policíacas de ese país por evitar su ingreso.

Al trabajar en Estados Unidos, los mexicanos logran retener una cantidad mucho mayor de valor excedente absoluto del creado por su fuerza de trabajo de la que podrían retener en México, aún a pesar de que su status ilegal y sus características raciales y culturales estigmatizadas los hacen vulnerables a la sobreexplotación en comparación con otros trabajadores en Estados Unidos; este tipo de resistencia no considera al cambio de sistema como un tema político conciente. En cambio, se trata de una estrategia de reproducción del hogar y la comunidad, es decir, permite a los trabajadores sostener a sus familias por encima del mínimo indispensable de subsistencia, que de otra manera sería el único posible en sus países de origen.

La migración internacional autónoma puede entenderse como un ejemplo de los que James C. Scott (1985) denomina armas de los débiles, término que utiliza para describir las formas indirectas, subrepticias y cotidianas de resistencia a la explotación y la dominación adoptadas por parte de las poblaciones subalternas en el mundo. ${ }^{3}$ Como síntesis de los conceptos de la migración internacional autónoma y las armas de los débiles, y como su traducción al español, he dado el nombre de resistencia hormiga a las estrategias clandestinas autónomas de cruce de fronteras por parte de los migrantes mexicanos (Spener 2006 y en prensa). Como se ha documentado adecuadamente en la literatura sobre la migración mexicana a Estados Unidos, los medios que los migrantes utilizan con el objeto de participar en

\footnotetext{
${ }^{3}$ No soy el primer académico en percibir la utilidad del concepto de Scott para analizar la migración mexicana. La antropóloga Rachel Adler ha descrito también algunas de las «armas de los débiles» utilizadas por los migrantes yucatecos que estudió al analizar los que ella llamó sus agendas migratorias (Adler 2000:173 y Adler 2004:57-59).

${ }^{4} \mathrm{Mi}$ uso de este neologismo se inspira en dos Fuentes. Primero, en una entrevista que realicé en San Antonio, un mexicano me describió cómo la vigilancia de la frontera estadounidense no era efectiva porque los migrantes eran como hormigas y siempre encontrarían «un agujerito» en la frontera para meterse. Segundo, el término contrabando hormiga se utiliza con frecuencia en México y otros lugares de América Latina para describir el movimiento fuera de la ley y de pequeña escala de mercancía a través de las fronteras nacionales. La resistencia hormiga presenta adecuado paralelo con este uso. Además, el término resistencia hormiga puede verse como una analogía pacífica junto a las tácticas de la Guerra de las pulgas (Taber 1965/2002) que se practicaban por los guerrilleros en las luchas antiimperialistas del siglo xx en todo el mundo. Véase Heyman 1999a para una exploración más extensa de la analogía entre el cruce fronterizo clandestino y las luchas guerrilleras.
} 
este tipo de resistencia son principalmente sociales y culturales. En este sentido, podemos concebir a la resistencia hormiga como compuesta por una combinación de lo que Bourdieu (1986) llamó capital social y Vélez-Ibáñez (1988) ha denominado como fondos culturales de conocimiento, acumulados en las comunidades de migrantes.

Los migrantes mexicanos han contratado a coyotes, desde principios del siglo xx, para ayudarlos en su ingreso o para obtener un empleo en Estados Unidos. Esta ayuda -coyotaje- ha adoptado dos formas básicas que se han tornado en elementos integrales de la práctica de los migrantes en lo que se refiere a la resistencia hormiga a lo largo de los años. El coyotaje de evasión burocrática se refiere a los coyotes que ayudan a los migrantes a evitar los documentos requeridos o las filas de solicitantes impuestas por el gobierno de Estados Unidos para entrar y trabajar en el país con autorización oficial. Vemos operar este tipo de coyotaje cuando les venden a los migrantes documentos falsos o pasan por otras personas, como en el registro de extranjeros o las tarjetas de seguridad social que se presentan a los patrones o cuando los coyotes pagan a los inspectores de inmigración estadounidenses para que permitan a los migrantes pasar por las garitas o por los retenes en las carreteras sin presentar documentos. El coyotaje de cruce clandestino refiere a los migrantes que contratan coyotes para guiarlos en el cruce de la frontera y transportarlos de manera clandestina por determinada distancia en el interior de Estados Unidos (Spener 2005 y en prensa).

A principios del siglo XXI se pusieron en práctica, en el corredor migratorio del noreste de México y el sur de Texas, una variedad de tipos más específicos de los coyotajes de evasión burocrática y de cruce clandestino. En mi investigación de campo encontré que estos tipos variaban considerablemente en términos de su costo, complejidad, disponibilidad, seguridad y probabilidad de éxito, así como el grado en que la relación entre los migrantes y los coyotes estaba engarzada en las relaciones sociales de confianza o la implicación de transacciones entre participantes anónimos sin una relación pasada o futura entre ellos (Spener 2008a, 2008b, y en prensa). Independientemente del tipo específico de estrategia utilizada es importante tener en cuenta que el coyotaje es un proceso social, donde los migrantes autónomos buscan a los coyotes con el objeto de lograr las agendas migratorias que ellos mismos establecen. De tal forma, el coyotaje es un elemento esencial de la resistencia hormiga de los migrantes ante el apartheid global que se ha puesto en vigor en la frontera entre México y Estados Unidos.

\section{EL DISCURSO DOMINANTE: \\ LA VISIÓN DE LOS ESTADOS SOBRE EL «CONTRABANDO DE EXTRANJEROS» Y EL PAPEL DE LOS MEDIOS DE COMUNICACIÓN QUE LO DIFUNDEN}

La historia que cuentan los funcionarios estadounidenses acerca del fenómeno del cruce de la frontera, con apoyo de los coyotes en los últimos 15-20 años, contiene 
una cierta cantidad de elementos recurrentes, mismos que han sido ampliamente difundidos por los medios de comunicación. En primer lugar, los coyotes no son llamados proveedores de servicios de navegación, transporte o vivienda que han sido contratados de forma activa por los migrantes, sino que se les llama «contrabandistas» $\mathrm{O}$ «traficantes» ${ }^{5}$ de víctimas pasivas a las que tratan como «carga» o como «mercancía». Esta construcción retórica vincula al coyotaje con otros fenómenos como la esclavitud, la servidumbre por contrato y el tráfico de drogas, que son vistos por el público como violentos, amenazadores y moralmente reprobables.

Un segundo elemento en el discurso oficial es que los «contrabandistas» están motivados únicamente por la ambición y por ello se comportan de ese modo, sin compasión o preocupación (o muy escasas) por el bienestar de los migrantes que transportan, en especial si el mostrarse preocupados pudiera bajar sus ganancias. Encontramos que este elemento entra en juego en las narraciones de cruces fronterizos fallidos en los que los migrantes fueron abandonados en el camino para que murieran de sed por parte de «contrabandistas» que les mintieron acerca de los rigores con los que se toparían en la travesía, o en las narraciones en las que muchos migrantes son llevados en algún vehículo viejo y al que casi no se le da mantenimiento, en un viaje que desemboca en un accidente fatal, cuando el vehículo es perseguido por la patrulla fronteriza.

Un tercer elemento es que la vigilancia por parte de la patrulla fronteriza se ha intensificado en las últimas dos décadas, el «contrabando» se ha tornado en un negocio mucho más sofisticado, a gran escala y más rentable, además de ser controlado por un pequeño número de grupos del crimen organizado. Se asume que los coyotes que operan a menor escala y que tienen sus bases en las comunidades han sido sacados del negocio por la creciente dificultad para cruzar, así como por la competencia o intimidación por parte de los grupos del crimen organizado. Se dice que estos grupos del crimen organizado están implicados en la prostitución, el tráfico de drogas y de armas, denotando con ello que el ejercicio del «tráfico de extranjeros» se parece cada vez más a esos nefarios negocios, en términos de la ferocidad de sus empresarios y su disposición a recurrir a la violencia para defender sus intereses. Algunos académicos (véase por ejemplo Andreas 2000) han afirmado que las políticas y tácticas de vigilancia de la frontera, por parte del gobierno de Estados Unidos han producido sin proponérselo, esta indeseable

\footnotetext{
5 Estos dos términos con frecuencia se utilizan de forma intercambiable en el discurso público a pesar del hecho de que se definen de manera distinta en el derecho internacional. Según el Protocolo de las Naciones Unidas para evitar, suprimir y castigar el tráfico, el «contrabando de personas» es definido como las situaciones en que los migrantes pagan a otro participante por ayudarles a entrar de manera ilegal en un estado en el que no son ciudadanos ni residentes permanentes (Laczko 2002). Definió el «tráfico de personas» de manera similar al del «contrabando», con el ingrediente adicional de los «traficantes» que asumen el control de las personas que son traficadas con el objeto de explotarlas contra su voluntad (Laczko 2002). Aunque los «contrabandistas» contratados por los migrantes mexicanos algunas veces realmente resultan ser «traficantes» según los define el Protocolo de las Naciones Unidas, no es ése el caso para la gran mayoría de los muchos miles de mexicanos que anualmente contratan a un "contrabandista» para cruzar la frontera.
} 
transformación de la «industria del contrabando». En otra parte he criticado esta representación, por anunciar de manera prematura el fracaso de las empresas de coyotaje en menor escala y con mayor fundamento en la comunidad y porque no se reconoce que los funcionarios estadounidenses realizaron aseveraciones similares acerca del "contrabando» en los años veinte, en los años cincuenta y en los setenta, lo que hace que la gente se pregunte cuántas veces esta «industria» puede "transformarse» en algo mucho más siniestro de lo que había sido hasta el momento (Spener 2004, 2005 y en prensa).

Un cuarto elemento discursivo ha entrado en acción desde los ataques terroristas contra el World Trade Center y el Pentágono el 11 de septiembre de 2001 y consiste en que los grupos «transnacionales del crimen organizado» que participan en el «tráfico de personas» plantean una amenaza peligrosa e inminente a la seguridad nacional de Estados Unidos. Dada la supuesta disposición de estos grupos a abandonar a los migrantes, ejecutar a los rivales, vender veneno a los niños y obligar a las mujeres a ser esclavas sexuales, se sugiere que esos grupos no dudarían en ayudar a las organizaciones terroristas a trasladar a sus miembros por las fronteras para participar en ataques adicionales en contra del suelo «americano». Este elemento del discurso oficial acerca del contrabando/tráfico encontró su máxima expresión en el reporte de políticas titulado A Line in the Sand: Confronting the Threat at the Southwest Border, cuyos dudosos hallazgos fueron publicados en otoño de 2006 por los funcionarios de la mayoría que participaban en el Subcomité de investigaciones del Comité de Seguridad Nacional de la Casa de Representantes de Estados Unidos.

Nuevamente, vale la pena hacer notar que las organizaciones y los políticos que se oponen a la inmigración lanzaron afirmaciones similares acerca de la amenaza a la seguridad nacional que planteaba el «contrabando» de «subversivos» por la «frontera abierta» de Estados Unidos y México en los años veinte y cincuenta, cuando se creía que los subversivos eran bolcheviques (véase American G.I. Forum of Texas y Texas State Federation of Labor 1953; Samora 1971; y Slayden 1921). Ya para principios de los años ochenta, los funcionarios estadounidenses, del presidente Reagan hacia abajo en la escala jerárquica, hasta el sector de la patrulla fronteriza en el sur de Texas advertían no sólo acerca de la infiltración de las guerrillas marxistas provenientes de Centroamérica, sino también de los agentes provenientes del Medio Oriente, que patrocinaban el terrorismo de estado (véase Dunn 1996).

No es de sorprender que los funcionarios de gobierno, en especial los agentes de vigilancia de la ley, tengan una opinión muy negativa sobre los coyotes, dado que éstos minan directamente lo que esos funcionarios consideran una de las prerrogativas básicas del estado: la regulación del traslado de personas a través de sus fronteras. El éxito de los migrantes, ayudados por los coyotes para penetrar las fronteras, desacredita las aseveraciones gubernamentales en el sentido de proteger de manera efectiva el territorio nacional contra las incursiones extranjeras 
y cuestiona la competencia y la eficacia de los funcionarios encargados de la vigilancia en las aduanas y los controles migratorios (véase también Heyman 1999a). De tal forma, los coyotes representan no sólo un desafío a la autoridad del estado, sino también una amenaza a la credibilidad de los burócratas estatales preocupados por conservar sus puestos y avanzar en sus carreras.

Al mismo tiempo, los funcionarios de gobierno pueden encontrarse con que la amenaza planteada por los coyotes constituye una herramienta útil para proteger e incluso expandir su personal y sus presupuestos. En la medida en la cual los coyotes, junto con los contrabandistas de armas y de drogas ilegales puedan ser representados exitosamente como una amenaza substancial y creciente a la seguridad nacional que supera en cantidad de armamento a las autoridades encargadas de hacer cumplir la ley en la frontera, los burócratas del estado pueden justificar presupuestos cada vez mayores para sus agencias para combatir la amenaza. Esto se ha realizado con bastante éxito por parte de las agencias de vigilancia de la ley en la frontera desde los años ochenta (véase Andreas 2000 y Dunn 1996).

Comenzando con la operación bloqueo en El Paso, Texas en 1993, las autoridades han intensificado substancialmente la vigilancia a lo largo de la frontera con México, lanzando una serie de operaciones militarizadas diseñadas para evitar que los migrantes autónomos y sus coyotes escenifiquen cruces fronterizos en los corredores urbanos más poblados. En el sur de Texas, se adoptó la forma de la operación Río Grande, lanzada en Brownsville el verano de 1997, la que subsecuentemente se extendió río arriba hacia Laredo (véase Maril 2004 y Spener 2000, 2001 y en prensa). Como consecuencia, los migrantes comenzaron a circular por rutas nuevas y más largas por zonas menos pobladas e inhóspitas que quedan entre los corredores urbanos intensamente patrullados junto a la frontera. Era predecible que aumentaran dramáticamente las muertes de los migrantes debido a ahogamiento, deshidratación e insolación, así como aumentaron las muertes derivadas de accidentes que ocurrieron cuando los vehículos cargados de migrantes emergían de la maleza en su trayecto por evitar los puntos de revisión de inmigración y entraban a altas velocidades a las autopistas, frecuentemente con los vehículos de la patrulla fronteriza en franca persecución (Cornelius 2001; Eschbach, Hagan y Rodríguez 2001 y 2003; Stop Gatekeeper 2004). Cuando las organizaciones defensoras de los derechos humanos culparon a las nuevas tácticas de vigilancia de las autoridades de inmigración por el incremento en las muertes, las autoridades intentaron protegerse de estos ataques señalando a los «contrabandistas de extranjeros» como la parte responsable de las tragedias que ocurrían a una cifra creciente de migrantes. Por ejemplo, cuando entrevisté a un agente de programas públicos de la patrulla fronteriza en el sur de Texas en mayo de 2001, poco después de que 14 migrantes murieran al atravesar el desierto de Arizona cerca de Yuma, dijo esto:

La patrulla fronteriza no llevó a estas personas a través de Yuma. iNo queremos que crucen! No queremos que arriesguen sus vidas... Es decir, no empujamos a la gente a 
que cruce en otros lugares. Son los contrabandistas quienes deciden en dónde cruzar. Y están decidiendo que quieren que el grupo mueran en vez de ser arrestados por la patrulla fronteriza. iDepende de ellos! En tantas formas.

Además, este mismo agente aseguró que los migrantes, lejos de ser las víctimas, habían sido los principales beneficiarios de las operaciones de vigilancia de la patrulla fronteriza, desde principios de los años noventa. El tener a más agentes vigilando la frontera, insistía, significaba que la patrulla fronteriza podría realizar un trabajo más efectivo para proteger a los migrantes frente a quienes los convertían en víctimas como los «contrabandistas» y otros «bandidos de la frontera» que trabajaban coludidos con los primeros. Al identificar a los «contrabandistas» como la fuente principal de la violencia inflingida a los migrantes no sólo distraía la atención respecto a la responsabilidad de las autoridades por los peligros que enfrentaban los migrantes, sino que también les permitía a estas mismas autoridades presentarse en el papel de protectores de los migrantes en vez de como sus perseguidores. A propósito de la cuestión del «tráfico» de personas en otras partes del mundo, Wong (2005) afirma que el discurso generado por el estado acerca del fenómeno enfatiza la necesidad de proteger a las mujeres y a otras víctimas del tráfico cuyo predominio se exagera para generar un pánico moral en el público, mientras que la práctica del estado de atacar los problemas sirve, sobre todo, para reforzar las fronteras a cruzar, por aquellas que los migrantes recurren a los «traficantes».

Mi investigación de campo sobre las experiencias de cruces fronterizos clandestinos, por parte de los mexicanos, en el corredor migratorio del noreste de México y sur de Texas a principios del siglo xxi me ha llevado a la conclusión de que estas representaciones consistentemente negativas de los coyotes y el coyotaje que ofrecen las fuentes oficiales y que son publicadas en la prensa con frecuencia son simplistas y exageradas y algunas veces bastante engañosas. En entrevistas y observaciones realizadas en el corredor del noreste de México y sur de Texas durante el periodo 1998-2005 encontré que:

a) el comportamiento de los coyotes frecuentemente no podía ser tajantemente clasificado como virtuoso o villano;

b) el coyotaje adoptaba una variedad de formas diferentes, muchas de las cuales, si no es que la mayor parte, se realizaba fuera de la dirección de los grupos del crimen organizado;

c) las relaciones entre migrantes y coyotes a veces podían ser relativamente amistosas y de cooperación en vez de anónimas y abusivas;

d) más de un puñado de migrantes se mostraban razonablemente satisfechos con los servicios que les prestaban sus coyotes;

e) los migrantes no necesariamente culpaban a sus coyotes por las dificultades y los peligros con los que se topaban en sus travesías por la frontera. ${ }^{6}$ No obstante,

${ }^{6}$ Otras investigaciones recientes parecen corroborar varios elementos de esta evaluación. Una encuesta realizada durante 2006 en comunidades yucatecas de salida de migrantes por parte de un

136 PRIMER SEMESTRE 2008

MIGRACIÓN Y DESARROLLO 
las caracterizaciones negativas de los «contrabandistas» $y$ «traficantes» por parte de los funcionarios gubernamentales prevalecieron en la cobertura de los medios de comunicación sobre los temas fronterizos durante este periodo.

Hay varias razones por las cuales la perspectiva del estado sobre el fenómeno se difunde por los medios y se excluyen las perspectivas que podrían ofrecer otros actores, que están familiarizados con las prácticas asociadas con la migración autónoma por parte de los mexicanos. Es importante entender que el único conocimiento que tiene la mayoría de los ciudadanos estadounidenses y mexicanos respecto al proceso social de los cruces clandestinos proviene de lo que ven, escuchan y leen en los medios de comunicación. ${ }^{7}$

Una de las principales razones por las cuales predominan las visiones de los funcionarios de gobierno en la cobertura noticiosa de los temas fronterizos es que sus visiones son tomadas por la prensa como dignas de convertirse en noticia, en virtud de la posicion como autoridad burocrática que ocupan. Además, el Departamento Estadounidense de Seguridad Nacional es la única institución en el sur de Texas ocupada en los asuntos de inmigración y de vigilancia de la frontera que tiene una infraestructura de relaciones públicas bien desarrollada a su disposición. Sobra decir que los migrantes autónomos y sus coyotes no cuentan con un aparato de relaciones públicas similar para confiarle su lado de la historia. En efecto, en vez de buscar influir en la opinión pública en torno a sus actividades, hacen todo lo posible por proteger su anonimato y clandestinidad, en sus esfuerzos por evitar su captura y juicio por parte de las autoridades encargadas de la vigilancia. De ahí que, mientras que los reporteros que trabajan con una fecha límite y con presupuestos limitados encuentran fácil obtener entrevistas e información provenientes de la patrulla fronteriza, deben trabajar duro para ubicar a los migrantes y coyotes que tengan información relevante para los acontecimientos noticiosos que cubren, y tienen todavía menos posibilidades de realizar entrevistas a profundidad.

Paralelamente, la mayor parte de los cruces fronterizos apoyados en coyotes nunca llegan a las noticias en absoluto, a menos que impliquen una muerte, un accidente o algún arresto. En otras palabras, los cruces exitosos donde los coyotes brindan sus servicios de manera competente a los migrantes y sin abusar de ellos no llegan a la atención del público a excepción de unos cuantos casos en que los pe-

equipo de investigadores de la Universidad de California-San Diego arrojó el dato de que el 92\% de los encuestados reportó que sus coyotes habían cumplido los términos del acuerdo en su último cruce fronterizo, mientras que tan sólo el 8\% reportó haber sido objeto de abuso por parte de sus coyotes. Datos no publicados de la encuesta realizada en Yucatán en 2006 por parte del Mexican Migration Field Research and Training Program, con sede en el Center for Comparative Immigration Studies, Universidad de California-San Diego. Recibidos en comunicación personal de Wayne Cornelius el 11 de agosto de 2006.

${ }^{7}$ Varios de los señalamientos que hago en esta sección coinciden con argumentos similares que Klinenberg (2002) sostuvo acerca de la cobertura de la prensa en torno a una ola de calor que tuvo lugar en Chicago en 1995, durante la cual murieron más de 700 personas. Véase también Gans (2003) respecto a la relación entre reporteros y funcionarios de gobierno. 
riodistas disponen de fondos y tiempo para realizar reportajes especiales de investigación a fondo. Incluso en esos casos, la fuerza legitimadora de la propia ley influye en las perspectivas de los reporteros, en especial si las personas más volubles y de mayor capacidad comunicativa con quienes se encuentran para realizar entrevistas son funcionarios encargados de la aplicación de la ley y que enfatizan la criminalidad del "contrabando» como actividad y a su propia función como la de conservar el «imperio de la ley». ${ }^{8}$ En algunos casos, los reporteros pueden ceder ante los marcos de los funcionarios encargados de la vigilancia legal en el tema del «contrabando» de modo que no pongan en peligro el acceso a ellos como fuentes valiosas de noticias frescas. En otros más, los reporteros quizá no pueden entrevistar a los migrantes y coyotes aprehendidos por las autoridades estadounidenses, dado que la mayor parte de ellos son rápidamente deportados a México tras ser detenidos. ${ }^{9}$ La contingencia legal a la que se enfrentan quienes permanecen en custodia como sospechosos o testigos materiales les deja escaso incentivo para hablar con los reporteros.

\section{La retribución de responsabilidad por la violencia sufrida por los migrantes}

Al resistirse al confinamiento territorial y las privaciones materiales que les son impuestas por el sistema del apartheid global los migrantes confrontan una variedad de formas de violencia, tanto directa como indirecta. Con el objeto de comprender y contextualizar adecuadamente los tipos de violencia que sufren los migrantes mexicanos autónomos que cruzan clandestinamente la frontera de Estados Unidos con ayuda de coyotes, debemos emplear una definición de violencia como concepto analítico que a la vez sea extenso y conciso. Siguiendo a Nevins (2003 y 2005), uso en este caso la definición y tipología que ofrece Johan Galtung que cumple con esas dos condiciones; esta definición tiene la ventaja de ser consistente con muchos conceptos de los derechos humanos, como aquellos codificados

\footnotetext{
${ }^{8}$ Nevins (2005) ha escrito de manera bastante convincente acerca del poder legitimador de la ley en lo que respecta a generar el apoyo del público estadounidense a medidas más estrictas para la vigilancia fronteriza. Aquí sugiero que los reporteros no están menos expuestos a la posibilidad de ser socializados en la posición más común, de que la ley representa lo que es correcto y justo, que los otros residentes de Estados Unidos y que sus reportes reflejan y refuerzan esa cosmovisión.

9 Esto ha sido siempre lo que sucede rutinariamente con los migrantes mexicanos, a quienes es típico que se les «regrese voluntariamente» a México unas cuantas horas después de ser detenidos por la patrulla fronteriza. Ahora, con el lanzamiento del Programa Oasis, de carácter binacional, los mexicanos que ostensiblemente participan en el «contrabando de extranjeros» y son capturados por las autoridades estadounidenses en tierra de ese país pueden ser entregados a las autoridades mexicanas para ser procesados en México. La razón para hacerlo así es que los requisitos legales para procesar a los acusados de "contrabando» en México no incluyen el que los fiscales deban presentar «testigos materiales» de sus "crímenes», como es el caso en las cortes federales de Estados Unidos. Este aspecto del programa puede recordar a los lectores de la práctica de «rendición extraordinaria» de los sospechosos de terrorismo por parte de Estados Unidos ante terceros países en donde la protección legal de los acusados es menos estricta que en Estados Unidos. Véase Cano 2006; Diario de Juárez 2007; Secretaría de Relaciones Exteriores 2005.
} 
en la Declaración Universal, mismos que contemplan no sólo actos de agresión física contra las personas, sino también a las personas que han sido sistemáticamente menoscabadas en elementos vitales para su salud y desarrollo, independientemente de si hay un perpetrador individual o conjunto de perpetradores identificable como responsable de esa privación.

Para Galtung (1969:168), «la violencia está presente cuando los seres humanos son influidos de modo tal que sus realizaciones somáticas y mentales se sitúan por debajo de sus realizaciones potenciales». Para abordar el tema de la responsabilidad, Galtung (1969:170-171) separa este concepto general de violencia en dos tipos: violencia personal (o directa), en la que hay un actor individual o un conjunto de actores identificable que comete directamente actos de violencia contra una víctima o conjunto de víctimas, y violencia estructural, en la que no hay un perpetrador individual que cometa un acto discreto, sino que la organización de la sociedad es tal que «la violencia está incorporada en la estructura y se muestra como poder desigual y en consecuencia como probabilidades de vida desiguales». La violencia estructural, argumenta a grandes rasgos, es un sinónimo de «injusticia social», concepto que además es congruente con las políticas o actos que violan los derechos humanos universalmente reconocidos. En un artículo posterior, Galtung (1990:291) añade el concepto de violencia cultural, a los dos tipos discutidos antes, mismo que define como «aquellos aspectos de la cultura -la esfera simbólica de nuestra existencia-ejemplificados por la religión y la ideología, el lenguaje y el arte, la ciencia empírica y la ciencia formal (matemáticas, lógica) -que pueden ser utilizados para justificar o legitimar la violencia directa o estructural. ${ }^{10}$

Siguiendo el marco de Galtung podemos ver que la mayor atención prestada al tema de la violencia en contra de los migrantes, en el discurso público, acerca de la inmigración y los tópicos fronterizos en los años recientes, se ha centrado en la violencia personal que les es inflingida por actores específicos, en especial por los "contrabandistas». Mientras que el discurso público incluye un reconocimiento general de la falta de oportunidad económica adecuada en México y la continua demanda de mano de obra de bajo costo en Estados Unidos, es típico que no se contemplen estos temas como ejemplos de violencia estructural o de injusticia social. La ideología nacionalista y la creencia en «el imperio de la ley» operan como violencia cultural para legitimar las desigualdades existentes entre México y Estados Unidos y para proporcionar una justificación para vigilar el traslado de personas por la frontera entre los dos países. ${ }^{11}$ En efecto, se combinan para «naturalizar» la

${ }^{10}$ La definición de Galtung de violencia cultural se traslapa considerablemente con el concepto de Bourdieu (1977:191) de violencia simbólica, lo que añade el ingrediente de la eufemización o mistificación de la formulación de Galtung. En otras palabras, la violencia simbólica no solo sirve para legitimar sino a veces para enmascarar otros tipos de violencia al atribuir la responsabilidad de éstos a fuentes distintas de las verdaderas (véase también Imbusch 2003). En este artículo utilizo el término violencia cultural para referirme a instancias de eufemización, mistificación o ignorancia de la violencia, así como a su legitimación.

${ }^{11}$ El mismo Galtung (1996:203) identificaba al nacionalismo y los sistemas legales de manera más general como formas que podía adoptar la violencia cultural. 
separación militarizada de los territorios y poblaciones nacionales. Como argumentaré más adelante, el discurso acerca de la seguridad en la frontera que se enfoca en actos de violencia personal, cometida por los coyotes contra los migrantes, puede entenderse también como un aspecto de la violencia cultural, en la medida en que distrae nuestra atención de la resistencia de los migrantes a la violencia estructural que adopta la forma del apartheid global puesta en práctica en las fronteras nacionales.

\section{Violencia personal contra los migrantes: los coyotes y la patrulla fronteriza}

Se han documentado numerosos incidentes de violencia personal contra los migrantes por parte de los coyotes en la región fronteriza del sur de Texas y noreste de México, los cuales han sido reportados en la prensa desde el lanzamiento de la operación Río Grande en el verano de 1997. Éstos incluyen casos de abandono en el camino, sodomía, golpizas, secuestro, disparos y accidentes automovilísticos fatales que han sido causados, al menos en parte, por manejo imprudente por parte de los coyotes (Burnett 2001; Hegstrom 2001; Davis 2004; King 2001; Winingham y Schiller 1999). El ejemplo más aterrador de este tipo de violencia lo constituyó la muerte por hipertermia y asfixia de 19 migrantes que eran transportados en la caja sellada de un camión cerca de Victoria, Texas en mayo de 2003 (véase Ramos 2005). No es de sorprender que algunos coyotes, de forma rutinaria u ocasionalmente, cometan actos de violencia personal en contra de los migrantes dado que a) la mayoría de los coyotes son jóvenes varones que se encuentran en sus años con mayor tendencia a la criminalidad; $b$ ) ellos guían, transportan y albergan a los migrantes de manera clandestina en situaciones social y legalmente carentes de regulación en las que los migrantes son directamente vulnerables al abuso y que c) pueden tener verdaderos incentivos para cometer actos violentos si creen que pueden hacerlo sin estar sujetos a una respuesta inmediata. Estos incidentes, documentados en la prensa, se toman como evidencia prima facie del carácter cada vez más violento de los coyotes en el periodo actual de creciente supervisión de la frontera, aunque también debemos recordar que lo coyotes en esta región se han caracterizado por ser implacables y violentos por muchas décadas (véase Samora 1971; Spener 2005 y en prensa).

Efectivamente, a pesar de la ausencia de datos cuantitativos, derivados de la investigación, que permitan rastrear los cambios en la frecuencia relativa de los actos violentos cometidos por los coyotes contra sus clientes, es típico que los funcionarios gubernamentales y la prensa vean a los coyotes como intrínseca y uniformemente abusivos con los migrantes a los que guían y transportan, una visión que en buena parte no ha sido cuestionada por los académicos o los defensores de los derechos humanos. Como argumenté en otra parte (Spener 2008a y en prensa), las relaciones entre los coyotes y las comunidades de migrantes con frecuencia 
están suficientemente arraigadas socialmente y se caracterizan por lo que Portes (1995) ha denominado «solidaridad circunscrita» y "confianza obligada» por lo que los migrantes están, al menos de alguna manera, protegidos de las fechorías por parte de los coyotes, aun cuando no siempre es ése el caso.

Durante ese mismo periodo, los activistas de los derechos humanos y la prensa han reportado numerosos abusos a los migrantes por parte de las autoridades de vigilancia de la frontera y de la inmigración en esta región, mismos que también caen bajo la etiqueta de violencia personal. Estos incidentes han incluido golpizas y ataques sexuales, así como amenazas, abuso verbal, disparos y detenciones arbitrarias con fundamento en la etnicidad, incluidos ciudadanos estadounidenses (Amnistía Internacional 1998; Gregor 2000; Houston Chronicle 2007; Maril 2004; Pinkerton 2000; Selzer 1998; Valley Movement for Human Rights 2005). A diferencia del caso con los coyotes, los agentes del departamento de seguridad nacional de Estados Unidos son representados como no violentos en circunstancias normales, mientras que la violencia personal que cometen los agentes en contra de los migrantes por lo general se representa como excepcional para la prensa. No obstante, tampoco debería sorprendernos que cuando menos algunos agentes de la seguridad nacional cometan actos de violencia contra los migrantes debido a: a) la naturaleza inherentemente conflictiva de sus encuentros con los migrantes; $b$ ) las diferencias culturales entre los agentes y los migrantes; c) la socialización de los agentes hacia actitudes nacionalistas e incluso sutilmente racistas hacia los migrantes; $y d$ ) el hecho de que los agentes cada vez aprehenden más migrantes en áreas rurales aisladas, en situaciones en las que pueden abusar de ellos sin ser detectados por otros miembros de su línea de mando.

Los activistas de los derechos humanos, a ambos lados de la frontera, están muy concientes de los tipos de violencia que acechan a los migrantes en manos de los coyotes, los agentes de la patrulla fronteriza y otros funcionarios encargados de la vigilancia legal. Un activista al que entrevisté en el sur de Texas en 2001 no ofreció opinión alguna sobre quién cometía más o peores actos de violencia contra los migrantes, reconociendo tan sólo que ocasionalmente tanto los coyotes como los agentes de la patrulla fronteriza abusaban de los migrantes. Sin embargo, hizo notar que sólo a los coyotes se les tildaba de criminales:

¿Quiénes son los coyotes? Son personas. Al igual que los agentes de la patrulla fronteriza. Todas son personas. Ambos son personas en una situación en la que cuentan con mucho poder sobre otros. Y en esa situación algunos se aprovecharán de ello y otros no. Tenemos agentes de la patrulla fronteriza que hacen cosas realmente terribles y otros que no lo hacen en absoluto. Tan sólo es un trabajo al que entran y en el que ponen su tiempo. No veo que los coyotes sean muy distintos... Pero en cuanto alguien es etiquetado como criminal, es algo que se utiliza para deshumanizarlos, ino?... Aplícales eso a los inmigrantes: iey, rompen la ley, son criminales, no son humanos! De tal modo se abre todo un proceso de deshumanización. Creo que es la misma cosa con los coyotes. Si les llamas «malvados» entonces puedes hacer con ellos lo que quieras. 
Ninguna discusión sobre la violencia cometida contra los migrantes estaría completa si no se considera el género. Las mujeres mexicanas que cruzan clandestinamente la frontera enfrentan un serio riesgo de violencia sexual en su contra por parte de los coyotes, funcionarios encargados de aplicar la ley y otros migrantes, en especial si ellas no van acompañadas de algún pariente varón. Aunque cometer actos de abuso sexual contra las mujeres no es inherente a los coyotes varones, como tampoco lo es para quienes están en los papeles de agentes de la patrulla fronteriza o de migrantes varones, por lo general se asume que los coyotes son predadores sexuales, mientras que los otros migrantes y los agentes encargados de la vigilancia de la ley no lo son. A este respecto, haríamos bien en reconocer que los coyotes o los agentes de la patrulla fronteriza que cometen violencia sexual contra las mujeres no lo hacen tan sólo por ser coyotes o agentes de la patrulla fronteriza per se, sino como hombres, cuyas actitudes y comportamientos han sido forjados en una cultura más amplia de violencia hacia las mujeres. Además, debemos tener en cuenta que existen coyotas similares a los coyotes y algunas de ellas se especializan en trasladar a otras mujeres en el cruce de la frontera. El coyotaje muchas veces puede servir también como estrategia para ayudar a las mujeres a escapar de la violencia en las comunidades de origen, como en el caso de una joven mexicana que entrevisté quien había cruzado la frontera con su hijo párvulo para huir de un marido golpeador. La madre de la mujer había arreglado que su hija cruzara con los mismos coyotes que a ella la habían trasladado a salvo a Estados Unidos varios años atrás. La mujer percibió la experiencia como aterrorizante pero fue entregada sana y salva en su destino, donde volvió a reunirse con su hija, como le habían prometido los coyotes a su madre.

Finalmente, vale la pena hacer notar que a pesar del aumento de la migración a Estados Unidos por parte de mujeres mexicanas en décadas recientes, el cruce clandestino de la frontera, sin documentos, parece conservarse como una práctica abrumadoramente masculina: entre el 80 y el $85 \%$ de los migrantes adultos aprehendidos anualmente por la patrulla fronteriza en los primeros cinco años del siglo XXI eran hombres (datos proporcionados al autor por la patrulla fronteriza el 24 de mayo de 2007).

\section{Violencia estructural: el contexto en el cual ocurre}

la violencia personal contra los migrantes

Las autoridades encargadas de vigilar la ley en Estados Unidos, en especial la patrulla fronteriza y la unida de vigilancia de inmigración y aduanas (Immigration and Customs Enforcement Unit-ICE) del departamento de seguridad nacional, desempeñan un papel activo e indispensable en el mantenimiento del apartheid global en lo que se refiere a las relaciones entre México y Estados Unidos. Aunque el apartheid global, como sistema, normalmente no implica que los agentes del estado 
inflijan violencia directamente en los migrantes autónomos, es claro que cumple la definición de Galtung como forma estructural de violencia en contra de los migrantes reales y potenciales en la medida en que constituye un aspecto de la estructura social que les niega acceso a los medios para cubrir las mínimas necesidades de subsistencia y los fuerza a participar en comportamientos de alto riesgo -como el atravesar a pie por los desiertos- con el objeto de cubrirlos. El aparato de control de la inmigración y de la frontera que posee el departamento de seguridad nacional, así como los fiscales y cortes estadounidenses que procesan a quienes, entre los migrantes, practican la resistencia hormiga, constituyen elementos indispensables en la institucionalización del apartheid global, es decir, forman parte de la violencia estructural que se impone a los migrantes.

Algunos analistas sugieren (véase, por ejemplo, Andreas 2000:21-26) que existe una relación perversamente simbiótica entre la patrulla fronteriza y los «contrabandistas» en la medida en que la escalada en el control fronterizo por parte del estado expande el mercado y aumenta las ganancias para los «contrabandistas». Esto plantea la pregunta acerca de cómo interpretar el papel que desempeñan los coyotes en la estructura del apartheid global. Queda claro que una vigilancia fronteriza más intensa induce a más migrantes a contratar los servicios de los coyotes que cuando la guardia no se da a tal grado. Además, al menos algunos de los coyotes establecen arreglos de beneficio mutuo con los agentes estadounidenses, de la burocracia encargada de vigilar la inmigración, para permitirles el paso a través de la frontera a sus clientes. Se podría argumentar, con base en esto, que los migrantes se ven cada vez más forzados a contratar los servicios, con precios al alza, de los coyotes y que como consecuencia los coyotes sacan provecho del incremento por parte del estado en la vigilancia fronteriza, por lo que los intereses de los coyotes y del estado están aliados en contra de los intereses de los migrantes, es decir, los coyotes también son parte integral de la estructura represiva del apartheid global.

Hay tres razones por las cuales creo que esa conclusión no es adecuada: primero, en general las autoridades de vigilancia de la ley estadounidense no colaboran con los coyotes ni los toleran sino que, en cambio, dedican una cantidad significativa de personal y recursos para, de manera activa, perseguir, encausar, encarcelar y en última instancia, exterminar a los coyotes y eliminar la práctica del coyotaje. En segundo lugar, los coyotes no monopolizan los cruces clandestinos de la frontera, ubicándose en el camino de los migrantes que desean entrar a Estados Unidos y extrayéndoles una "cuota» si desean pasar. Los datos disponibles sugieren que, al menos durante 2003, un alto porcentaje de migrantes mexicanos autónomos continuaron cruzando la frontera sin contratar coyotes. Tercero, a pesar de los robos y los fracasos que ocurren, los coyotes por lo general cumplen con los términos de su contrato con los migrantes y los llevan hasta destinos en Estados Unidos tras evadir con éxito la aprehensión por parte de las autoridades en la región fronteriza. 
Por tal razón, los migrantes buscan los servicios de los coyotes, con frecuencia con base en las recomendaciones de sus compañeros o por la familiaridad personal con los coyotes que operan en sus comunidades, con el objeto de progresar en sus agendas migratorias a pesar de los obstáculos puestos en su camino por el gobierno de Estados Unidos. También por esta razón, en combinación con las privaciones y los peligros que enfrentan en caso de quedarse en sus lugares de origen, que los migrantes generalmente ignoran las advertencias del gobierno en el sentido de no confiar en los coyotes y continúan realizando negociaciones con ellos para el cruce de la frontera.

En vez de concluir que los coyotes participan en la puesta en práctica del apartheid global y por tanto, en la producción de violencia estructural contra los migrantes, creo que es más exacto ver la relación entre los migrantes y sus coyotes como una alianza estratégica en el campo social ${ }^{12}$ del cruce fronterizo, uno de los principales campos en los que se da la resistencia de los migrantes ante el apartheid global. Esta alianza producida estructuralmente es inquietante y con frecuencia conflictiva, a la que se ingresa por razones prácticas más que por razones morales, afectivas o políticas. No obstante, se ve fortalecida por las características compartidas de clase y cultura por parte de los migrantes y los coyotes y su confrontación con un enemigo común que los persigue a ambos en medida casi equivalente. El hecho de que algunos coyotes se aprovechen de la vulnerabilidad de los migrantes que los contratan para cometer abusos serios e imperdonables -y algunos lo hacen- no contradice el argumento más amplio de que los migrantes y los coyotes comparten intereses y objetivos comunes en sus batallas cotidianas con el apartheid en la frontera. En este respecto debemos recordar que muchas formas de violencia personal se infligen en las víctimas por parte de personas con las que tienen relaciones estrechas - maridos que maltratan a las esposas, padres que maltratan a los hijos, supervisores de los talleres que abusan de los operadores de maquinaria, sargentos que abusan de los reclutas- todo dentro de instituciones sociales, generalmente caracterizadas por altos niveles de solidaridad con los miembros del mismo grupo.

Podemos entender mejor los actos de violencia personal cometidos contra los migrantes por parte de los coyotes si ubicamos tales actos en el contexto de la violencia estructural generada por la escala de interdicción en la frontera, por los estados como fracción de un sistema de apartheid global. La intensidad de la vigilancia fronteriza afecta las relaciones entre los migrantes y los coyotes y el comportamiento de los coyotes hacia los migrantes de muchas formas. Primero, como han hecho notar Heyman (1999a) y otros, hace que los migrantes aumenten su probabilidad de entrar en relaciones con los coyotes para cruzar la frontera. Segundo, la escalada obliga a los coyotes a guiar a los migrantes por terrenos más remotos y peligrosos a lo largo de distancias mayores en comparación con fechas ante-

12 En mi uso del término campo social sigo a Bourdieu y Wacquant (1992). 
riores, con el consecuente aumento en los peligros de accidente y muerte para los migrantes y coyotes por igual. Tercero, la intensificación de los enjuiciamientos de los coyotes por las autoridades, con aumentos en los castigos en caso de ser convictos, puede dar mayores incentivos a los coyotes para participar en comportamientos violentos para protegerse a sí mismos a expensas de los migrantes. Esto podría ayudar a explicar, por ejemplo, algunas de las persecuciones a altas velocidades que se desencadenan por parte de la patrulla fronteriza y otros agentes de vigilancia de la ley en donde los coyotes al volante intentan escapar «saltando» del vehículo en el que transportan migrantes y huyen hacia la maleza.

La creciente intensidad de vigilancia fronteriza puede también hacer que algunos coyotes traten de ejercer un control físico más directo sobre los migrantes en su esfuerzo por evitar ser detectados por parte de las autoridades, mientras transitan así como en el momento de estar en casas de seguridad, además infunden temor en los migrantes acerca de las consecuencias potenciales de identificar a sus coyotes ante las autoridades. De tal forma, los esfuerzos gubernamentales por juzgar a los coyotes, lejos de proteger a los migrantes, pueden de hecho tener el efecto de ponerlos en mayor riesgo. Hablando del grado de los esfuerzos en el control fronterizo por parte del estado en Canadá y Europa, así como en la frontera entre Estados Unidos y México, Sharma (2005: 96-97) hace notar que el principal resultado de las campañas contra el tráfico y contra el contrabando ha sido «hacer mucho más peligrosas las migraciones ilegales» y tornar «aún menos probable el surgimiento de modernas Harriet Tubmans». ${ }^{13}$

Una de las formas de violencia personal, por la cuales es común que se culpe a los coyotes, es dejar abandonados a los migrantes que se retrasan en el camino mientras atraviesan la frontera a pie. Han surgido varias ambigüedades en mis entrevistas con los migrantes, mismas que complican el determinar la culpa de esos incidentes. Un tema es si los migrantes también comparten la responsabilidad por dejar abandonado a un compañero, en especial dado que es típico que su número sea mucho mayor que el de sus guías en la maleza y que éstos rara vez van armados. Efectivamente, he entrevistado a migrantes en el estado de San Luis Potosí, quienes dijeron haber controlado a su coyote cuando les propuso que dejaran abandonado a alguien en el camino: o esperaba a los que se rezagaban o nadie continuaría con él, lo que significaba que el coyote y sus colaboradores perderían todo el dinero que esperaban cobrar al grupo, no sólo la cantidad correspondiente al individuo que habrían dejado abandonado. ${ }^{14}$ Para mi sorpresa, varios

${ }^{13}$ Para los lectores que no están familiarizados con los detalles de la historia de esclavitud en Estados Unidos antes de la Guerra Civil: Harriet Tubman era una mujer afroamericana a la que se venera por haber ayudado a los esclavos sureños a escapar y obtener su libertad en el norte como líder de lo que fue conocido como el «ferrocarril subterráneo» (Underground Railroad).

${ }^{14}$ Otro ejemplo de cómo los migrantes ejercen control sobre sus coyotes en el camino proviene de un reporte periodístico en el desierto de Arizona, donde77 migrantes mexicanos y centroamericanos vencieron a su guía, quien se había perdido mientras los guiaba e intentaba abandonarlos, tomaron su teléfono celular y llamaron al número de emergencias de Estados Unidos (911) para ser rescatados (Mural 2005). 
otros mexicanos que entrevisté en zonas rurales de Guanajuato, San Luis Potosí y Texas me dijeron que no necesariamente consideran responsables a los coyotes cuando han abandonado a alguien en el camino. En su opinión, los migrantes sabían que el pasaje por la frontera y por el sur de Texas era peligroso y que debían ser físicamente fuertes para cubrirlo. Sabían que los coyotes tienden a declarar que es menor el tiempo que realmente toma el recorrido y habían conocido también a personas de su área geográfica que habían muerto en el intento, al cruzar con «buenos» coyotes.

En su opinión, el que se lograra o no dependía de qué tan preparado estuviera el cuerpo para soportar los rigores del recorrido. Los coyotes y otros migrantes en el grupo tenían la obligación de intentar ayudar a los compañeros en la medida de sus capacidades, pero no siempre era posible. Si viajas con un amigo cercano o un pariente éste se quedará contigo y te ayudará a salir hacia la carretera, pero no puedes esperar que todos los demás se entreguen a la patrulla fronteriza. En las condiciones extremas de las áreas silvestres del sur de Texas, incluso ese amigo o pariente podría no estar en condiciones de ayudarte gran cosa. Un potosino que entrevisté en una ciudad de Texas en 2004 tenía esto que contar acerca de dos hombres que había conocido en su pueblo:

Arnulfo: -Bueno, hay historias como las nuestras en donde la gente no sufrió demasiado y hay otras historias en las que la gente sufrió tremendamente. Por ejemplo, hace unos cuatro o cinco años, un amigo de mi pueblo comenzó a trabajar como coyote. El trabajo era escaso, así que comenzó a cruzar a la gente. Y una vez llevaba a un pariente con él, otro de mis amigos. Era su tío. Y se le murió en el trayecto. Tuvo que dejarlo ahí en el monte. Era un señor.

Spener: -iFue culpa del coyote o simplemente era tan difícil que...?

Arnulfo: -iNo! Pues era miembro de su familia. No creo que haya sido su culpa. Lo llevaba como miembro de la familia. Dice que lo abandonó porque ya no podía seguir más. El señor mismo le dijo (es decir, el tío moribundo) le dijo que simplemente lo dejara, no podía seguir.

Bajo condiciones como éstas -impuestas por un estado de apartheid y sus agentes- podríamos cuestionar si señalar a individuos como culpables de estas tragedias es realmente tan fácil como se hace parecer típicamente.

Con el objeto de entender mejor porqué los migrantes en ocasiones perdonan, lo que la gente ajena podría ver como abusos imperdonables cometidos en su contra por los coyotes, debemos considerar también que la manera en que el apartheid global como forma violencia estructural contribuye a la cosmovisión y a las actitudes que sostienen los migrantes acerca de la vida en general y acerca de las estrategias de migración autónoma en particular. A este respecto, el concepto de habitus ${ }^{15}$ de Bourdieu (1977) resulta útil. El habitus de los migrantes

15 Para Bourdieu (1977:72), el habitus que poseen los individuos consiste en un sistema de «disposiciones durables y transferibles» que funcionan como "principios de la generación y estructuración 
condiciona sus prácticas de cruce de la frontera en términos de los riesgos que están dispuestos a asumir y los tipos de comportamientos por parte de los coyotes que están dispuestos a tolerar. Varias generaciones de experiencia migratoria en México han llevado a la acumulación no sólo de considerables reservas de capital social y humano relacionado con la migración (Phillips y Massey 2000; Singer y Massey 1998), sino también a un conjunto de expectativas acerca del cruce de la frontera en torno a las cuales son socializados los aspirantes a migrar. Esta socialización se da no sólo en el nivel de la interacción cara a cara entre miembros de la misma red social, sino también por medio de la cultura popular y los medios de comunicación, que adoptan una variedad de formas (por ejemplo corridos, películas, telenovelas, anuncios de servicio público en televisión y radio) que advierten de los peligros de cruzar y de depositar la fe en un coyote.

Otros aspectos del habitus migratorio son atribuibles a las experiencias cotidianas de las condiciones generales de vida, como miembros de la clase trabajadora o del campesinado. Uno de los principales aspectos de estas condiciones generales de vida es su precariedad, según se manifiesta en un inadecuado o inconstante ingreso, características que se aplican también a la dieta, al cuidado de la salud, al abasto de agua, drenaje, transporte y seguridad, como consecuencia de la economía internacional prevaleciente y del descuido por parte del estado de sus obligaciones más elementales con los ciudadanos. De tal forma, los migrantes aprenden a esperar y luego a soportar las malas condiciones como un asunto natural en sus vidas, incluido el hacer esfuerzos heroicos para mejorar su condición viajando al norte. Esto también podríamos considerarlo como parte de un habitus migratorio que se deriva de la histórica carencia de oportunidades económicas adecuadas en México para sus clases proletaria y campesina, lo que se intensifica por el establecimiento por el estado de políticas neoliberales que constituyen uno de los corolarios del apartheid global. Es en este contexto de socialización que los migrantes realizan negociaciones con los coyotes. Se les ha advertido que el cruce de la frontera es peligro, que las condiciones serán duras, que la vigilancia de la patrulla fronteriza es intensa, que quizá tengan que hacer varios intentos antes de llegar a su destino y que algunas personas mueren en el camino. En este sentido, la situación generalizada de violencia estructural que constituye su experiencia vivida puede preparar a los migrantes para «perdonar» todo menos los más graves abusos cometidos por los coyotes en su contra.

\footnotetext{
de las prácticas y representaciones» que les permiten «manejar situaciones no previstas y siempre cambiantes». Por lo común las personas no son concientes de los principios que constituyen su cosmovisión y guían sus acciones — sus habitus - porque han sido socializadas en ellas de manera inconsciente. El tipo de habitus que posee un individuo depende de las posiciones sociales que ha ocupado (clase, género, raza, etnia, nacionalidad, orientación sexual, entre otras), así como de la historia que ha producido esas posiciones sociales y sus relaciones con otras posiciones sociales que existen en los campos de actividad en que se ubican esas posiciones.
} 
La violencia cultural: el coyotaje y la mistificación de la violencia estructural en el discurso público

El asumir responsabilidad personal por las propias acciones es uno de los pilares fundamentales de la moralidad occidental moderna, en especial cuando éstas implican daño a otros. Como hizo notar Iris Young, el extinto filósofo político de la Universidad de Chicago, la asignación de culpabilidad a individuos o a grupos discretos por daños causados a otros también es un pilar fundamental de los sistemas legales occidentales; ella llama a esta aproximación a la asignación de responsabilidad modelo de responsabilidad restringida:

Bajo este modelo de responsabilidad específica, se asigna la responsabilidad a un agente particular (o agentes) cuyas acciones puede demostrarse que están conectadas causalmente con las cuales se busca la responsabilidad... cuando las acciones fueron voluntarias y se emprendieron a sabiendas... es adecuado culpar a los agentes de los resultados dañinos (Young 2006:116).

Cuando los migrantes resultan lastimados o mueren en su intento de entrar a Estados Unidos con la asistencia de coyotes, el sistema legal estadounidense por lo común sostiene que los coyotes tienen una responsabilidad criminal por estos daños. Incluso en los casos en que los coyotes son aprehendidos pero no ha ocurrido un daño real a los migrantes que los contrataron, los castigos asignados por las cortes de Estados Unidos son mayores si los fiscales pueden probar que los coyotes pusieron en peligro a sabiendas a los migrantes con estas formas de actuar. La retórica empleada por los funcionarios encargados de la vigilancia de la ley en Estados Unidos que capturan y encausan a los coyotes con frecuencia enfatiza la culpabilidad moral de los coyotes por las acciones que dañaron o podrían dañar potencialmente a los migrantes. Al hacerlo, se ponen a sí mismos en el papel de protectores de los migrantes y de vengadores de los males cometidos en su contra. Los funcionarios encargados de la vigilancia legal son capaces de hacer eso porque cualquier consideración de la contribución al daño de los migrantes por las estructuras más amplias del apartheid global de las que forman parte es inadmisible en el debate legal referido a la evaluación de la culpabilidad en esos casos. En otras palabras, el sistema de vigilancia de la ley y los agentes que lo ponen en marcha operan dentro de un modelo de responsabilidad limitada (liability) de la justicia que los prepara para abordar los problemas de la violencia personal, pero no los problemas de la violencia estructural en la que están tan profundamente inmersos los problemas de la violencia personal.

No es de sorprender que el ejemplo más dramático de la retórica de cargo, respecto a la culpabilidad moral de los coyotes, provenga del caso más trágico que implicó las muertes de migrantes autónomos que intentaban ingresar a Estados Unidos. En mayo de 2003, 19 personas murieron de hipertermia y asfixia en Vic- 
toria, Texas al ser transportadas desde la frontera hacia Houston en la parte trasera de una caja de trailer sellada. Las autoridades estadounidenses y mexicanas identificaron y juzgaron con éxito a los 14 acusados que de alguna manera habían participado en la organización de esa travesía fatal. Los fiscales buscaban la pena de muerte para el conductor del tractor del trailer, un inmigrante jamaiquino de nombre Tyrone Williams, del quien se declaró era el acusado con mayor responsabilidad por la muerte de los migrantes. Al anunciar que su oficina buscaría la pena de muerte para Williams, el fiscal Michael Shelby dijo cuando un acto, realizado intencionalmente descuidando gravemente la vida humana, resulta directamente en la mayor cantidad de muertes de las operaciones contemporáneas de contrabando, la justicia y la ley exigen que el acusado enfrente el castigo máximo al ser declarado culpable (citado en Rice 2004).

En su discurso de apertura en los dos juicios de Williams, ${ }^{16}$ el fiscal asistente Daniel Rodríguez caracterizó a los «contrabandistas» como un grupo que constituía «una empresa criminal que trataba a las personas peor que a ganado en su viaje al matadero» y dijo que Williams era «el más desalmado, malvado y cruel de la organización (citado en Lozano 2005a). En su discurso de cierre en el segundo juicio de Williams, Rodríguez argumentó que el «status legal, nacional, de origen y raza» de las víctimas en el caso era irrelevante respecto a lo que les sucedió porque «el valor de la vida humana en este país es el mismo». Además, argumentó, que los jurados deberían enviar un mensaje a (Williams) - y no sólo a él, sino a la gente de su calaña, que la justicia en este país significa justicia para todos... la única decisión justificable en este caso es la muerte. Esas personas no merecían morir (citado en George 2007). El abogado de Williams, por otra parte, en su alegato final frente al jurado en el primer juicio a su cliente, sostuvo que el gobierno ha acusado en exceso a Tyrone Williams. Buscaron a su alrededor y vieron una tremenda tragedia, una inmensa pérdida de vidas humanas, vieron la pena y la vergüenza y dijeron que alguien debía pagar con su vida (citado en Lozano 2005b).

En ningún momento del juicio se dio una discusión significativa de las políticas del gobierno estadounidense o de los gobiernos de los países de origen de los migrantes muertos, que estimularon que cerca de cien de ellos abordaran un camión tras escurrirse a través del Río Bravo bajo el manto de la noche. Ninguno de los fiscales citados arriba, cuya oficina trabajaba en estrecha colaboración con la Patrulla Fronteriza y el ICE para juzgar y encarcelar a miles de migrantes por «ingreso ilegal» a Estados Unidos a través del sur de Texas (véase Transaction Records Clearinghouse 2005), reconoció aspecto alguno de las propias políticas de apartheid del gobierno para producir la situación que desembocó en las muertes de los migrantes. Además, escasa, o muy cercana a nula, fue la cobertura noticiosa de la tragedia misma y de los juicios que le siguieron en donde se sugeria que las políticas del gobierno estadounidense estuvieran de alguna manera relacionadas con esas muertes.

${ }^{16}$ El primer juicio terminó sin que pudiera tener efecto legal (mistrial). 
El concepto de Galtung de violencia cultural nos ayuda a entender de qué manera la omisión de la consideración pública del grado al cual es posible la responsabilidad del estado por las muertes de los migrantes, en la medida en que llama nuestra atención de las formas en que la ideología nacionalista y la creencia en el imperio de la ley como sacrosanto han llegado a «naturalizar» la separación militarizada de territorios y personas. También ayuda a explicar de qué manera el estado y los medios de comunicación han sido exitosos en gran medida en sus intentos por asignar la responsabilidad única por las muertes de los migrantes a los coyotes que los guían y transportan.

En última instancia, los jurados en el segundo y definitivo juicio aceptaron el argumento del abogado de Williams y rechazaron la pena de muerte, aunque lo encontraron culpable de "contrabando de extranjeros», por lo cual fue condenado a cadena perpetua. Uno de los jurados en el juicio reportó que aunque el jurado tenía en mente "primero y sobre todo» a las víctimas, rechazó la pena de muerte porque ellos creían que Williams esperaba que la gente viviera dado que antes había transportado a migrantes en su camión (George 2007). El presidente del jurado declaró a los reporteros que «en ningún momento hubo la intención de que alguien muriera». Además, dijo, "como grupo, nos sentimos buenos y en paz con nosotros [y] nuestra decisión» (citado en Hart 2007). La decisión respecto a la pena de muerte fue unánime y se llegó a ella sin desacuerdo entre los jurados (Blumenthal 2007). El periodista Jorge Ramos en su libro de 2005 Morir en el intento, publicado casi dos años antes de la decisión del jurado de no sacrificar a Williams, creía que los intentos de las autoridades estadounidenses por convencer a un jurado de la intención de los coyotes de matar a los migrantes que murieron en el camión estaban destinados a fracasar desde el principio:

[...] eso era obvio para quienes seguían el fenómeno de la inmigración indocumentada hacia Estados Unidos. Era claro que el caso de Victoria era una operación que había resultado mal, muy mal. No es en beneficio del coyote, por más insensible que sea, que mueran los migrantes a los que intenta transportar. Por más frío que pueda sonar, los coyotes no obtienen su paga de migrantes muertos. Los necesitan vivos (Ramos 2005:134, traducción del español de Spener). ${ }^{17}$

Aunque los jurados en el juicio de Williams encontraron que los fiscales se habían extralimitado al buscar la pena de muerte para el acusado, no tuvo lugar una reconsideración pública tras la tragedia de Victoria, en cuanto al papel desempeñado por la violencia estructural como forma diferente a la violencia personal para producir la muerte de los migrantes. En cambio, unos cuantos meses después

${ }_{17}$ Nada de esto, por supuesto, absuelve a los acusados en el caso de cualquier responsabilidad individual imputable por no tomar las medidas adecuadas para cerciorarse de que los migrantes que transportaban viajaran seguros. En cambio nos recuerda que debemos reconocer también el papel que jugó la violencia estructural impuesta por las políticas de apartheid en las muertes trágicas e innecesarias de estos migrantes.

150 PRIMER SEMESTRE 2008 MIGRACIÓN Y DESARROLLO 
de la tragedia, la legislatura tejana aprobó el decreto HB 2096, una ley que convertía en crímenes algunos aspectos del contrabando/tráfico de humanos en la ley estatal así como lo son en la ley federal. Los gobiernos de Estados Unidos y de México, aun cuando no pudieran alcanzar acuerdo alguno respecto a la reforma de un sistema migratorio quebrantado entre los dos países, lanzaron el programa Oasis para redoblar sus esfuerzos por desmantelar las organizaciones dedicadas al «contrabando de extranjeros» y al «tráfico de personas».

La patrulla fronteriza en Estados Unidos y la oficina del fiscal en el área de Del Río, Texas comenzaron una política de «tolerancia cero» ante los «ingresos ilegales», lo que significaba que todos los migrantes aprehendidos por la patrulla fronteriza serían procesados y sentenciados a un periodo de cárcel, antes de ser formalmente deportados a su país de origen. Esta medida incluía a los mexicanos, quienes hasta el momento habían «retornado voluntariamente» a México inmediatamente después de su aprehensión (Contreras 2006). En los siguientes años, los temas de una "frontera fuera de control» $\mathrm{y}$ "atacada» por parte de las bandas organizadas de criminales, muchas de las cuales eran supuestamente formadas por «ilegales» mexicanos y centroamericanos que entraron al país escurriéndose por la frontera, vendrían a dominar el discurso público acerca de la migración. No es de sorprender que los esfuerzos de reforma migratoria en el congreso se fueran a pique, mientras que se realizaban llamados a construir nuevos muros a lo largo de la frontera, la Guardia Nacional era llamada a auxiliar a la patrulla fronteriza en el arresto de los migrantes autónomos y los agentes del ICE fueron distribuidos para realizar redadas en los lugares de trabajo de los migrantes en todo el país. La retórica de cargo empleada por los fiscales en contra de los "contrabandistas» en el caso Victoria es consistente con su más amplio discurso de violencia cultural que de manera versátil sirve para justificar, mistificar y distraer nuestra atención de la violencia estructural subyacente, que a la vez motiva la migración autónoma y pone en peligro a quienes participan en ella.

En su trabajo teórico acerca de la justicia global, Iris Young (2006) argumenta que el modelo de responsabilidad personal limitada (liability), descrito antes, es inadecuado para abordar los problemas de «injusticia estructural» que trascienden las fronteras internacionales. Para abordar los problemas de injusticia estructural propone el desarrollo de un modelo de conexión social. Ese modelo reconocería las maneras en que los individuos en conjunto sostienen la responsabilidad de los "resultados injustos», en la medida en que contribuyen a ellos como consecuencia de acciones que ejecutan dentro de los "procesos institucionales diversos» que constituyen las estructuras sociales que inflingen violencia para con otros (Young 2006:119). Los pasos que se den hacia la aplicación de este modelo de justicia representarán una forma de alejamiento de la visión del mundo en la que los individuos son los únicos responsables de su propio bienestar y donde se reconoce la violencia sólo en la medida en que implica actos francos cometidos por un participante individual contra otro participante individual. Es este el tipo de modelo que nece- 
sitaremos si hemos de comenzar a desmantelar los sistemas de violencia estructural, como el del apartheid global.

La adopción y aplicación de este modelo a la situación que enfrentan los migrantes en la frontera entre México y Estados Unidos representaría un alejamiento de la violencia cultural, que criminaliza sus estrategias no violentas de supervivencia, promueve la satanización y persecución de cualquiera que los ayude en la práctica de la resistencia hormiga y enmascara las causas subyacentes de su sufrimiento.

\section{BIBLIOGRAFÍA}

AdLeR, Rachel (2000) «Human Agency in International Migration: The Maintenance of

Transnational Social Fields by Yucatecan Migrants in a Southwestern City", Mexican Studies/Estudios Mexicanos, 16:1:165-187.

(2004), Yucatecans in Dallas, Texas: Breaching the Border, Bridging the Distance, Boston, Massachusetts, Allyn \& Bacon.

Alexander, Titus (1996), Unraveling Global Apartheid: An Overview of World Politics, Cambridge, Inglaterra, Polity Press.

American G.I. Forum of Texas and Texas State Federation of Labor (AFL) (1953), What

Price Wetbacks?, Austin, Texas, Authors, Reprinted in 1976 in Mexican Migration to the United States, Nueva York: Arno Press.

Amnesty International (1998), United States of America: Human Rights Concerns in the Border Region with Mexico, Nueva York, Nueva York, Author.

Andreas, Peter (2000), Border Games: Policing the U.S.-Mexico Divide, Ithaca, Nueva York,

Cornell University Press.

Blumenthal, Ralph (2007), "Jury Spares Driver in Smuggling Deaths Case», The New York

Times, 19 de enero, edición electrónica.

Booker, Salih and William Minter (2007), "Global Apartheid», The Nation, 273:2:11-17. Bourdieu, Pierre (1986), "The Forms of Capital», pp. 241-258 en Handbook of Theory and

Research for the Sociology of Education, John G. Richardson (ed.), Westport, Connecticut, Greenwood Press, Inc.

(1977), Outline of a Theory of Practice, Cambridge, U.K., Cambridge University Press. y Loic Wacquant (1992), «The Purpose of Reflexive Sociology (Chicago Workshop)», pp. 61-215 en An Invitation to Reflexive Sociology, edición de Pierre Bourdieu y Loic Wacquant, Chicago, Illinois, University of Chicago Press.

Burnett, John (2001), «Immigrant Smugglers», Segment broadcast on National Public Radio's, Morning Edition, 22 de junio.

CANo, Luis Carlos (2006), "Activan plan para combatir tráfico de personas en Juárez», El Universal, 11 de julio.

Contreras, Guillermo (2006), «Immigrants Flooding Del Rio Courts», San Antonio ExpressNews, p. 1A.

Cornelius, Wayne (2001), «Death at the Border: Efficacy and Unintended Consequences of

U.S. Immigration Control Policy», Population and Development Review, 27:4:661-685. 
DAvis, Vincent T. (2004), «Four Accused of Smuggling Migrants», San Antonio ExpressNews, 24 de febrero, p. $1 \mathrm{~B}$.

De Genova, Nicholas P. (2002), «Migrant 'Illegality' and Deportability in Everyday Life», Annual Review of Anthropology, 31:419-447.

Dunn, Timothy J. (1996), The Militarization of the U.S.-Mexico Border, 1978-1992: Low-intensity Conflict Doctrine Comes Home, Austin, Texas, cmas Books.

El Diario de Juárez (2007), «Acuerdan México y EU extender el programa Oasis a Coahuila», 8 de junio.

EschBACH, Karl, Jacqueline Hagan y Néstor Rodríguez (2001), "Causes and Trends in Migrant Deaths on the U.S.-Mexico Border, 1985-1998", University of Houston, Center for Immigration Research Working Paper Series, núms. 1-4, Houston, Texas, Center for Immigration Research.

(2003), «Deaths during Undocumented Migration: Trends and Policy Implications in the New Era of Homeland Security", Paper presented at the $26^{\text {th }}$ Annual National Legal Conference on Immigration and Refugee Policy in Washington, DC, consultado el 19 de Julio de 2006 en http://www.uh.edu/cir/ Deaths_during_ migration.pdf.

Gans, Herbert J. (2003), Democracy and the News, Nueva York, Nueva York, Oxford University Press.

Galtung, Johan (1990), "Cultural Violence», Journal of Peace Research, 27:3:1990.

(1996), Peace by Peaceful Means: Peace and Conflict, Development and Civilization, Oslo, Noruega, International Peace Research Institute.

(1969), «Violence, Peace, and Peace Research», Journal of Peace Research, 6:3: 167-191.

George, Cindy (2007), «Truck Driver's Fate in Hands of Jurors», Houston Chronicle, enero 8 , edición electrónica.

Gregor, Alison (2000), «Immigrant Effort Draws Complaints», San Antonio Express-News, 12 de febrero, p. $1 \mathrm{~A}$.

HART, Lianne (2007), «Driver Gets Life in Prison in Deadly Human Smuggling Case», Los Angeles Times, 19 de enero, edición electrónica.

Hegstrom, Edward (2001), "Local INS sting yields 21 arrests for smuggling», Houston Chronicle, 15 de mayo, edición electrónica.

Heyman, Josiah McC. (1999a), «State Escalation of Force: A Vietnam/U.S.-Mexico Border Analogy», pp. 285-314, en States and Illegal Practices, edición de Josiah McC. Heyman, Nueva York, Berg.

(1999b), «Why Interdiction? Immigration Control at the United States-Mexican Border», Regional Studies, 33.7:619-630.

Houston Chronicle (2007), "Border Patrol Agent Found Guilty», Houston Chronicle, abril 14, p. B3.

Imbusch, Peter (2003), «The Concept of Violence», pp. 13-61 en The International Handbook of Violence Research, Wilhelm Heitmeyer y John Hagan (eds.), Berlín, Alemania, Springer.

KinG, Karisa (2001), «INs sting nets 21 guilty pleas», San Antonio Express-News, 15 de mayo, edición electrónica.

Kuinenberg, Eric (2002), Heat Wave: A Social Autopsy of Disaster in Chicago, Chicago, Illinois, University of Chicago Press. 
KoHLER, Gernot (1995), «The Three Meanings of Global Apartheid: Empirical, Normative, and Existential», Alternatives, 20:403-413.

(1978), "Global Apartheid», World Order Models Project, Working Paper, núm. 7, Nueva York, Nueva York, Institute for World Order.

Krissman, Fred (2000), «Immigrant Labor Recruitment: U.S. Agribusiness and Undocumented Migration from Mexico", pp. 277-300, en Immigration for a New Century: Multidisciplinary Perspectives, Nancy Foner, Rubén Rumbaut y Steven J. Gold (eds.), Nueva York, Russell Sage Foundation.

LaczKo, Frank (2002), "Human Trafficking: The Need for Better Data», Migration Information Source, electronic newsletter, noviembre 2002, Washington, DC, Migration Policy Institute, consultado el 15 de junio de 2005 en http://www.migrationinformatio n.org/Feature/ display.cfm? $\mathrm{id}=66$.

LozAno, Juan (2005a), «Defense Says Language Barrier Kept Driver from Helping Immigrants», Associated Press, 9 de marzo, texto en la página electrónica del San Antonio Express News, http://www.mysanantonio.com/news/apwire/.

(2005b), «Prosecutor in Smuggling Horror Says Driver Blinded by Greed», Associated Press, marzo 19, texto en la página electrónica del San Antonio Express News, http://www.mysanantonio.com/news/apwire/.

MarIL, Robert Lee (2004), Patrolling Chaos: The U.S. Border Patrol in Deep South Texas, Lubbock, Texas, Texas Tech University Press.

Mural (2005), «Rescate en el desierto», Mural, Guadalajara, Jalisco, 21 de abril, p. 2A.

Nevins, Joseph (2003), "Thinking Out of Bounds: A Critical Analysis of Academic and Human Rights Writings on Migrant Deaths in the U.S.-Mexico Border Region», Migraciones Internacionales, 2:2:171-190.

(2005), «A Beating Worse than Death: Imagining and Contesting Violence in the U.S.-Mexico Borderlands», Americquests, vol. 2, núm. 1, consultado el 29 de septiembre de 2007 en http://ejournals.library.vanderbilt.edu/ameriquests/include/ getdoc. php? $\mathrm{id}=349$ \&article $=73 \&$ mode $=$ pdf\&OJSSID $=3 \mathrm{~d} 4 \mathrm{c} 7 \mathrm{cbb5eeb7abcf64ac97}$ 3cdc91f2f.

Phillips, Julie A. y Douglas S. Massey (2000), «Engines of Immigration: Stocks of Human and Social Capital in Mexico", Social Science Quarterly, 81:1:33-48.

Pinkerton, James (2000), «Border Patrol Twices Stops U.S. Judge on Way to Court», Houston Chronicle, 1 de octubre, p. 1.

Portes, Alejandro (1995), «Economic Sociology and the Sociology of Immigration; A conceptual overview», pp. 1-41, en The Economic Sociology of Immigration: Essays on networks, Ethnicity, and entrepreneurship, Alejandro Portes (ed.), Nueva York, Russell Sage Foundation.

Ramos, Jorge (2005), Morir en el intento: La peor tragedia de inmigrantes en la historia de los Estados Unidos, Nueva York, HarperCollins Publishers, Inc.

Rice, Harvey (2004), «Feds Seek Death in Immigrant Smuggling», Houston Chronicle, 16 de marzo, edición electrónica.

Richmond, Anthony H. (1994), Global Apartheid: Refugees, Racism, and the New World Order, Toronto, Ontario, Canadá, Oxford University Press.

Rodríguez, Néstor (1996), "The Battle for the Border: Notes on Autonomous Migration, Transnational Communities, and the State», Social Justice, 23:3:21-38. 
SAmora, Julian, con la asistencia de Jorge A. Bustamante F. y Gilberto Cárdenas (1971), Los Mojados: The Wetback Story, South Bend, Indiana, University of Notre Dame Press.

Scott, James C. (1985), Weapons of the Weak: Everyday Forms of Peasant Resistance, Nueva Haven, Connecticut, Yale University Press.

Secretaría de Relaciones Exteriores (2005), «México y Estados Unidos Establecen el Programa Oasis para proteger a los migrantes y procesar penalmente a traficantes y tratantes de personas», Boletín de prensa, 17 de agosto.

Selzer, Nate (1998), "Immigration Law Enforcement and Human Rights Abuses», Borderlines, 6:9, noviembre, consultado el 4 de octubre de 2007 from http://us-mex.irconline.org/ borderlines/1998/b150/bl50immi.html.

Sharma, Nandita (2005), "Anti-Trafficking Rhetoric and the Making of a Global Apartheid» NWSA Journal, 17:3:88-111.

SLAYDen, James L. (1921), "Some Observations on Mexican Immigration», The Annals of the American Academy of Political and Social Science XCIII, enero, pp. 121-126.

SinGer, Audrey y Douglas S. Massey (1998), «The Social Process of Undocumented Border Crossing Among Mexican Migrants», International Migration Review, 32:3:561-592.

Spener, David, Forthcoming. Clandestine Crossings: Migrants and Coyotes on the Texas-Mexico Border, Ithaca, Nueva York, Cornell University Press.

(2000), "The Logic and Contradictions of Intensified Border Enforcement in Texas", pp. 115-138 en The Wall around the West: State Borders and Immigration Controls in North America and Europe, Peter Andreas y Timothy Snyder (eds.), Lanham, Maryland, Rowman and Littlefield Publishers.

(2001), «Smuggling Migrants Through South Texas: Challenges posed by Operation Rio Grande», pp. 129-165 en Global Human Smuggling: Comparative Perspectives, David J. Kyle y Rey Koslowski (eds.), Baltimore, Maryland, The Johns Hopkins University Press.

(2004), «Mexican Migrant-Smuggling: A Cross-Border Cottage Industry», 2004, Journal of International Migration and Integration, 5:3: 295-320.

(2005), «Mexican Migration to the United States: A Long Twentieth Century of Coyotaje», Working Paper núm. 124, San Diego, California, Center for Comparative Immigration Studies of the University of California-San Diego, Disponible en línea en http://www.ccis-ucsd.org/PUBLICATIONS/wrkg124.pdf.

(2006), "Coyotaje as an Everyday Strategy of Resistance to Apartheid at the Mexico-U.S. Border», Trabajo presentado en Cocoyoc, Morelos, México, 28 de octubre durante el Segundo Coloquio Internacional sobre Migración y Desarrollo organizado por la Red Internacional de Migración y Desarrollo.

(2008a), «Cruces clandestinos: Migrantes, coyotes y capital social en la frontera el noreste de México-sur de Texas», Texto próximo a aparecer en La migración a los Estados Unidos y la Frontera Noreste de México, Socorro Arzaluz (ed.), Tijuana, Baja California, El Colegio de la Frontera Norte.

(2008b), «El eslabón perdido de la migración: El coyotaje en la frontera del sur de Texas y el noreste de México», texto por publicarse en Pobreza y migración internacional. El caso de México, Agustín Escobar Latapí (ed), México, Casa Chata. 
Stop Gatekeeper (2004), «Border Deaths (San Diego to Brownsville)», San Diego, California: California Rural Legal Aid, Conusltado el 19 de junio de 2006 en http:// www.stopgatekeeper.org/ English/images/graph_death2.gif.

TABER, Robert (2002) (1965), War of the Flea: The Classic Study of Guerrilla Warfare, Dulles, Virginia: Brassey's, Inc.

Transaction Records Access Clearinghouse (2005), Prosecution of Immigration Cases Surge in U.S. while Sentences Slump, Syracuse, Nueva York, Author. Consultado el 10 de marzo de 2007 en http://trac.syr.edu/tracins/latest/131/.

United States House of Representatives Committee on Homeland Security, Subcommittee on Investigations (2006), A Line in the Sand: Confronting the Threat at the Southwest Border, Washington, DC, Author.

Valley Movement for Human Rights (2005), In Our Own Backyard: A Community Report on Human Rights Abuses in Texas Rio Grande Valley, Harlingen, Texas, Author. Consultado el 19 de Julio de 2006 en http://www.nnirr.org/news/reports/vmhr_report_ esp.pdf.

Vélez-IbáÑ̃zz, Carlos (1988), «Networks of Exchange among Mexicans in the U.S. and Mexico: Local Level Mediating and International Transformations», Urban Anthropology 17:1:27-51.

Winingham, Ralph y Dane Schiller (1999), «Immigrant Is Found Dead on Train in Frio», San Antonio Express-News, 23 de abril, edición electrónica.

Wong, Diana (2005), "The Rumor of Trafficking: Border Controls, Illegal Migration, and the Sovereignty of the Nation-State», pp. 69-100 en Illicit Flows and Criminal Things: States, Borders, and the Other Side of Globalization, Willem van Schendel e Itty Abraham (eds.), Bloomington, Indiana, Indiana University Press.

YounG, Iris Marion (2006), «Responsibility and Global Justice: A Social Connection Model», Social Philosophy and Policy, 23:1:102-130. 